\title{
Introduction: Post-Normal Climate Science
}

\section{Werner Krauss, Mike S. Schäfer, and Hans von Storch}

This special symposium grew out of a workshop held in Hamburg in 2011 (Krauss and von Storch 2012) and of a long-term interest in climate research as post-normal science. A decade earlier, Dennis Bray and Hans von Storch (1999) stated that the management of uncertainty and its extension into the political and social realm make climate science a case for post-normal science. Interpreting a survey among German and American climate scientists, they suggested that scientific policy advice is the result of both scientific knowledge and normative judgment.

This special volume demonstrates that this insight is still valid and of relevance, even though climate science has changed a great deal over the past decade. For example, consensus among climate scientists on the question of anthropogenic climate change has grown (Bray 2010), and climate science has matured as a discipline. It has broadened its empirical basis and elaborated its models (Heffernan 2010); and it has also expanded and welcomed colleagues from more disciplines that have developed an interest in climate, its developments and their myriad causes and effects (Dryzek et al. 2011). Moreover, climate science has achieved a more distinct status as a research field of its own both epistemologically and institutionally (Schützenmeister 2008). Nonetheless, not everything seems to be normal in climate science; when we sent out the invitations for our workshop "Post-Normal Science: The Case of Climate Research," we received a huge array of proposals covering epistemological, practical, and political problems concerning scientific climate research.

Climate scientists do not simply produce objective and uncontested knowledge for political and economic decision makers; instead, there are many risks involved in climate communication (Weingart et al. 2000). A notable portion of climate science has become deeply intermingled with non-scientific actors, institutions, and influences, be it from politics, the economy, interest groups, or the media (Schäfer et al. 2012). When in 2007, Al Gore and Rajendra Pachauri received the Nobel Prize for Peace, knowledge derived from climate science was 
increasingly perceived as an "evangelical" message (Ravetz 2010). Anthropogenic climate change became a mission for open or stealth advocates (Pielke 2007), and little room was left for discussing inherent uncertainties or the normative assumptions that underlie the science-public interaction. Instead, the tendency to silence skeptical voices increased. The public climate debate turned into an almost confessional war with its own dynamics between "us" and "them," alarmists and skeptics, believers and deniers. Simultaneously, in policy advice and governance strategies, an epistemic community of climate experts promoted a model-based, linear understanding of "science speaks truth to power," with one voice only (see van der Slujis, this volume).

The hegemony of this linear model of science communication was challenged only after a series of events which turned public attention on surprisingly complex and sometimes messy inner-scientific dynamics and changed communication between science and the public (Moser 2010). First, there was the so-called hockey-stick controversy about the graph that shows the average temperature over the past 1000 years, accompanied by discussions about manipulations in the peer-review process and rumors about the possible gatekeeping of prominent scientific journals. This was followed by the scandal about the illegal hacking of private e-mails from the server of the Climate Research Unit at East Anglia. E-mails of relevant scientists were interpreted as willingly hiding or manipulating data in order to keep the public alarmed, to use "tricks" behind closed doors and to exclude skeptical voices from relevant scientific fora (Ryghaug and Skjølsvold 2010). Climate science indeed found itself in an uncomfortable position, which could no longer be rationalized as merely being attacks from evil-minded skeptics; instead, the situation challenged its very epistemological foundations.

Thus, while consensus about the reality of anthropogenic climate change was growing, as well as the respective media reporting (Ratter et al. 2012; Schäfer et al. 2011), the internal problems were never really dealt with in climate science. Public trust eroded and the scientific community started to resemble a dysfunctional family. Most of all, "normal" science and its protagonists lost control over the skeptical debate, which had found and created its own communication fora in the so-called blogosphere. From the hockey-stick debate to "Climategate" and ever since, this public communication platform became a powerful and uncontrollable force in the climate debate for experts and non-experts alike. It was here that skeptics found their fo- 
rum and developed their own climate narrative. And it was on the blogosphere, where after more than a decade after the Bray and von Storch article, Jerry Ravetz interpreted the crisis of climate science in terms of post-normal science.

\section{From Normal to Post-Normal Science}

Jerry Ravetz made his appearance in the climate debate after he had read about "Climategate," which raised his interest because the hacked e-mails highlighted a debate inside science. In order to understand his fascination for this case it is important to keep the origins of post-normal science in mind: Silvio Funtowicz and Jerry Ravetz (1990) developed the concept after the explosion of the Chernobyl nuclear power plant and after the Challenger catastrophe, both technological adventures with a promise for the future and a deficient risk assessment. This is what Ravetz saw again in climate science: on the one hand, a missionary attitude and, on the other hand, a catastrophic uncertainty management.

The current state of climate science deviates significantly from "normal" science as Kuhn (1962) described it in his seminal book The Structure of Scientific Revolutions. Normal science is, in the words of Ravetz (2010), what "nearly all scientists do all the time, it is puzzlesolving within an unquestioned framework or paradigm. Issues of uncertainty and quality are not prominent in 'normal' scientific training, and so they are less easily conceived and managed by its practitioners." Ever since Kuhn it was clear that science has its own history and sociology. But according to Hulme (2007), the limits of normal science are reached with the appliance of science, when scientific knowledge "can be modified through its interaction with society," or "when it rubs up against society." Science turns post-normal, when disputes "focus as often on the process of sciences - who gets funded, who evaluates quality, who has the ear of policy-as on the facts on science" (Hulme 2007).

This is clearly the case in climate science, where the current situation easily fulfills all the four criteria that according to Ravetz and Funtowicz (1991) define a case of "post-normal science" (PNS): facts are uncertain; values are in dispute; stakes are high and decisions are urgent. For Ravetz (2010), it was easy to find all those "loose ends [that] were unresolved and sometimes unattended"; furthermore, the strict focus on carbon and on models in the alarmist version of the "Anthropogenic Carbon-Based Global Warming" left the argument 
vulnerable and made its normative foundation even more visible. At stake is, according to Ravetz, the reputation of science:

Are we really experiencing Anthropogenic Carbon-based Global Warming? If the public loses faith in that claim, then the situation of science will be altered for worse. There is very unlikely to be a crucial experience that either confirms of refutes the claim; the post-normal situation is just too complex. The consensus is likely to depend on how much trust can still be put in science. (Ravetz 2010)

Ravetz reverses the debate in arguing that it is the defenders of such "Anthropogenic Carbon-Based Global Warming" who put the credibility of climate science into danger, who started with their evangelical fervor a "war on carbon," just like the ones before on the "war on drugs" or the "war on terror." From this perspective, the dismissal of critics and their labeling as "deniers" seem like symptoms and the suspicion of gatekeeping and "pal-review" as defense strategies. Of course, the latter are mostly accusations made by skeptics, often mixing insecure facts with gossip, but the rumors do not seem to go away. It is no longer possible to hide uncertainty or "to hide the decline," as the most often quoted line from the hacked e-mail exchange goes. The blogosphere turned out to be an important source of both disclosure and gossip and marks an important extension of what mostly had been an inner-scientific debate in times of "normal science."

\section{Extended Peer Review and the Blogosphere}

The climate blogosphere has become a vital part of the climate debate, provides a new link between science, the media, and the public and simultaneously opens up new forms of participation. Jerry Ravetz made use of one of the most popular skeptical blogs-Whatsupwiththat (WUWT) run by Anthony Watts—-to publish his statement "Climategate: plausibility and the blogosphere in the post-normal age" (2010). This blogpost is a manifesto for climate research as post-normal science: Ravetz uses the informality of the blogosphere to make strong and provocative arguments in order to initiate a debate about the future of climate science. The fact that he published on a skeptical blog can be read as a statement: not in terms of his attitude toward climate change, but as a sign of respect for the openness of the debate outside science. This manifesto had enormous repercussions inside and outside of the blogosphere; in the following year, Ravetz organized a workshop for "reconciliation in the climate debate" in Lisbon, where 
he invited skeptics and mainstream scientists for a debate in the tradition of non-violent communication (Pearce 2011; Traufetter 2011). Although great differences about the cause and meaning of current climate change remained, there was no doubt about the extension of the debate into the public and the role of the blogosphere, with extended informal peer review as one of its main features.

Extended peer review has also been at the origin of the climate blogosphere, when, for example, the retired engineer Steve McIntyre (2006) and others started to review the "hockey-stick" graph, and its underlying data and theory and other scientific papers. Experts from other fields, educated citizens, and engaged scientists started to make use of blogs to expand the scientific climate debate beyond the narrow confines of peer-reviewed journals. Ravetz (2010) sees in this development an opportunity and makes a suggestion to systematically extend classical peer review to the blogosphere, whenever it makes sense and is possible: "In traditional 'normal' science, the peer community, performing the functions of quality-assurance and governance, is strictly confined to the researchers who share the paradigm." To overcome this situation, he suggests that in extended peer review, all those affected by the policy problem will have a right to raise their voice, depending on their expertise. This is of special importance for the definition of the problem, the selection of the personnel, including rights of ownership and participation: "The theory of Post-Normal Science goes beyond the official consensus in recognizing 'extended facts,' that might be local knowledge or values, as well as unofficially obtained information" (Ravetz 2010).

\section{Climate Research as Post-Normal Science}

These developments have repercussions for science itself, for the practice of scientific publication and peer review (Ravetz 2012). Societal demands will increasingly set the agenda for climate research in future, and consequently challenge the traditional dominance of scientific authority from the outside. This is certainly the view of many climate scientists themselves, who understand outside interests and interventions, mainly via research funding, as powerful agents in shaping and changing climate science itself (Post 2009). A Nature editorial as a follow-up to our workshop argued that, seen through the lens of post-normal science, it is indispensable for a successful practice of climate science to 
embrace the idea that public and stakeholder participation can help to define research priorities[,] ... and that those with direct needs for climaterelated information-businesses, regional planners, government departments - have a greater say in the kind of services and knowledge that they expect publicly funded researchers to produce. (Anonymous 2011: 123)

Thus, the Hamburg workshop "Post-Normal Science: The case of Climate Research" could already rely on previous applications of this concept and focus on detailed accounts where and how to apply it most successfully. It was one of the distinct features of this workshop that it had nothing to do with the usual divide between skeptics and mainstream scientists; instead, we discussed open questions in climate science, which are acknowledged across the dividing lines, but which are nonetheless beyond the boundaries of normal science. Post-normal science is often misunderstood as an instrument of skeptics or a fundamental critique of climate science; far from that, it is a method and a concept to improve the functioning of climate research and to make it fit for the challenges climate change will bring to our societies.

\section{Plan of the Issue}

This special symposium is guided by three organizing concepts: a) the theory of post-normal science, b) the identification and description of post-normal situations, and c) the analysis of post-normal practices.

The contributions we have assembled here aim to review and further develop the concept of post-normal science, which since its introduction has seen a series of suggestions for revisions and redefinitions. The concept has been subject to critical discussions and met even strong opposition; quite often, it has been misunderstood, namely not as analysis of the conditions under which science is taking place, but as a normative practice of science in society. The issue at hand aims to ask for concrete examples of the application of post-normal theory, practices, and situations that indeed help to bring forth a new understanding of the role and good practice of science. Such considerations are at the heart of Jerome Ravetz's contribution to this issue. Being one of the originators of post-normal science, he reflects on the history and evolution of the concept and clarifies its current state. He does so in both a general and a very personal way; deliberately choosing the form of an essay to achieve this endeavor, which is so closely entangled with his own person and career. As a philosopher, his ap- 
proach opens new possibilities to think about and to discuss climate change as one of the most pressing issues, and his considerations serve as a leitmotif for the other articles.

We have assembled the other articles mostly because they highlight different manifestations of post-normality in science, and discuss post-normal responses and actions, using the case of climate science as a (potential) prime example. Some of these contributions describe what we label as post-normal situations: occasions with specific times and spaces in which the more general characteristics of post-normality are condensed and, thus, highlighted. One situation in which these characteristics were on full display was the criticism of the UN's Intergovernmental Panel on Climate Change (IPCC) that culminated in 2010. Set up to "provide comprehensive scientific assessments of current scientific, technical and socio-economic information worldwide about the risk of climate change caused by human activity, its potential environmental and socio-economic consequences, and possible options for adapting to these consequences or mitigating the effects" (IPCC 2006), the Panel generally aims to synthesize scientific findings under political and partly bureaucratic conditions, with a partly and maybe even largely political target audience. For a long time, it adhered to the logic of "truth speaks to power," disqualifying criticism from non-IPCC actors and scientists-in the terms of its Chairman Rajendra Pachauri-as "voodoo science" (Booker 2010). In other words, the IPCC tried to normalize the post-normal situation by emphasizing scientific authority. When some of the IPCC's claims proved to be wrong, however, the panel struggled to adopt a different stance and, in the process, to regain public trust and credibility. Silke Beck's contribution deals explicitly with this case. She shows that the IPCC dealt with the issue of public trust as a "technical" question, instead of opening up to new forms of interdisciplinary scientific appraisal aimed at wider publics such as those referred to as "extended peer review."

The IPCC case touches on the role of uncertainty and public participation in the climate debate and related decision processes. Jeroen van der Sluijs shows that uncertainty, complexity, and dissent make climate change hard to tackle with "normal" scientific procedures. In a post-normal perspective the normal science task of "getting the facts right" is still regarded as necessary but no longer as fully feasible or as sufficient to manage the interface of science and policy. It needs to be complemented with a task of exploring the relevance of deep uncertainty and ignorance that limit our ability to establish objective, 
reliable, and valid facts. In his article "Uncertainty and Dissent in Climate Risk Assessment: A Post-Normal Perspective," van der Sluijs explores the implications of this notion for the climate science-policy interface. He argues that the IPCC adopted a "speaking consensus to power" approach that sees uncertainty and dissent as multiple, albeit contradictory knowledge claims that need be mediated into a consensus prior to "speaking to power." This approach can be distinguished from other strategies: the "speaking truth to power approach," seeing uncertainties as a temporary lack of perfection in the knowledge, and the "working deliberatively within imperfections" approach, accepting uncertainty and scientific dissent as facts of life (irreducible ignorance) of which the policy relevance needs to be explored explicitly. Van der Sluijs recommends more openness for dissent and explicit reflection on ignorance in IPCC process and reporting.

Roger Pielke Jr. highlights another, rather different post-normal practice: the creation and management of ignorance. In his article "Post-Normal Science in a German Landscape," he uses the exploration of the landscape of eastern Germany, close to Leipzig, as an example, which has seen profound social, political, and technological changes over the past several decades. Like many places around the world, decision makers in eastern Germany are seeking to reach a future state where seemingly conflicting outcomes related to the economy and the environment are simultaneously realized. The management of ignorance is an important but often overlooked consideration in decision making that the concept of post-normal science places into our focus of attention. Pielke also uses the format of an essay, which perfectly serves the purpose of the meandering ways in which the dark valley between plan and outcome is crossed; or, to be more explicit, how a former coal mining area transforms into a post-modern recreational landscape.

Werner Krauss and Hans von Storch focus on an institutional practice that has been established to deal with the post-normal situation climate science is in; regional climate services that have been established as links between science and indigenous or local forms of knowledge. Regional climate services are set up to manage the interaction between information supply and user demands (von Storch et al. 2011). They provide knowledge needed for designing climate policy and climate management, but also represent a power factor in the struggle about other policy goals, ranging from food, travel, energy, and housing, and even general issues of life style and governance (Hulme 2009). Conversely, weather and climatic cycles are an issue 
of everyday life and language, loaded with a body of local knowledge. Thus, scientifically constructed knowledge finds itself challenged by a number of alternative culturally constructed knowledge claims (von Storch 2009). Based on recent works from the geography of science, the authors show how "normal," model-based science communication on a regional level easily turns out to be another form of neo-colonialism, as long as local knowledge is seen as only deficient and in need of being replaced by statistical models. Alternatively, examples from anthropology show that local forms of knowledge are often times based on detailed observation of the environment, engrained in customary practices and deeply rooted in the respective cultures. At the same time, especially in climatic vulnerable areas, there is a great interest in additional scientific expertise, which, in turn, is improved through the empirical data derived from local knowledge. Positioning itself as a service institution, with the limited role of offering explanations without deriving political conclusions, might help to uphold scientific authority as knowledge broker. In this understanding, "regional climate service" goes beyond the traditional climate service approach of mostly informing, educating, or other forms of unidirectional transmission of scientific knowledge; instead, it draws its legitimacy from the recognition of mutual exchange and dialogic communication among different forms of knowledge. In doing so, climate science acknowledges the key role of cultural values in policymaking.

In conclusion, this special symposium clearly demonstrates that the concept of post-normal science helps to open up scientific discourse, to identify complex cultural and political situations, and to improve and extend the range of practices of an applied science. The authors of the articles are from diverse disciplines such as philosophy, climate science, political science, or cultural anthropology; they show that the climate problem transcends disciplinary boundaries, and that the openness of post-normal science can serve as a common denominator to bring together approaches from many fields in order to face the challenges that climate change inevitably will bring.

Werner Krauss is a cultural anthropologist at Helmholtz Zentrum Geesthacht, Institute of Coastal Research, Germany. His current research and writing is mostly about the anthropology of climate change, with a special focus on climate discourse, the role of climate science, adaptation strategies and the emergence of renewable energies. These topics evolved from his long-term 
interest in human-environment relationships, political ecology, (post-) environmental theory, the anthropology of landscape, nature conservation, science and technology studies, and multi-sited ethnography. He conducted fieldwork in the Swiss Alps, in the South of Portugal (Alentejo), in Northern Germany, and Texas on topics such as environmental conflicts, national parks, nature conservation, renewable energies, climate change, and climate science. He has taught and published widely on these issues. Address: Helmholtz Zentrum Geesthacht, Institute of Coastal Research, Max Planck Str. 1, 21502 Geesthacht, Germany. E-mail: werner.krauss@gmail.com.

Mike S. Schäfer is an assistant professor at the Department of Journalism and Communications at the University of Hamburg. He heads the research group "Media Constructions of Climate Change" in Germany's Federal Cluster of Excellence "CliSAP" and is the speaker of the "Communication and Politics" division of the German Society of Communications. His research focuses on political and international communication, particularly on science and climate issues. He has published several books, most recently Das MedienKlima (edited with Irene Neverla, 2012) and Terrorismus im Fernsehen (together with Jürgen Gerhards, Ishtar Al-Jabiri, and Juliane Seifert, 2011) and articles in leading communications and sociological journals. Address: Department of Journalism and Communications, University of Hamburg, Grindelberg 5, 20144 Hamburg, Germany. E-mail: mike.schaefer@zmaw.de.

Hans von Storch is director of Institute of Coastal Research at the Helmholtz Zentrum Geesthacht and professor at the Meteorological Institute of the University of Hamburg, Germany. From 1987 to 1995, he was senior scientist and leader of the Statistical Analysis and Modeling group at the Max PlanckInstitute for Meteorology. His research interests are climate diagnostics and statistical climatology, regional climate change and its transdisciplinary context. He has published sixteen books and numerous articles. He is member of the advisory boards of, among others, Journal of Climate, Environmental Science and Policy, and Meteorologische Zeitschrift, and organizer of the GKSS School on Environmental Research. He was appointed a lead author of the Working Group II of the Fifth Assessment of the IPCC. He chairs efforts for a climate change assessment for the Baltic Sea Catchment and the metropolitan region of Hamburg. Address: Helmholtz Zentrum Geesthacht, Institute of Coastal Research, Max Planck Str. 1, 21502 Geesthacht, Germany.

\section{References}

Anonymous. "Value Judgements." 2011. Nature 473 (7346): 123-124.

Booker, Christopher. 2010. "Pachauri: The Real Story Behind the Glaciergate Scandal." The Telegraph. 23 January. http://www.telegraph.co.uk/comment/columnists/ christopherbooker/7062667/Pachauri-the-real-story-behind-the-Glaciergatescandal.html (accessed 1 March 2012).

Bray, Dennis. 2010. "The Scientific Consensus of Climate Change Revisited." Environmental Science \& Policy 13 (5): 340-350. 
Bray, Dennis, and Hans von Storch. 1999. "Climate Science: An Empirical Example of Postnormal Science." Bulletin of the American Meteorological Society 80 (3): 439-455.

Dryzek, John S., Richard B. Norgaard, and David Schlosberg, eds. 2011. The Oxford Handbook of Climate Change and Society. Oxford: Oxford University Press.

Funtowicz, Silvio O., and Jerome R. Ravetz. 1990. Uncertainty and Quality in Science for Policy. Dordrecht, The Netherlands: Kluwer.

_ 1991. "A New Scientific Methodology for Global Environmental Issues." Pp. 137-152 in Ecological Economics: The Science and Management of Sustainability, ed. Robert Costanza. New York: Columbia University Press.

Heffernan, Olive. 2010. "Earth Science: The Climate Machine." Nature 463 (7284): 1014-1016.

Hulme, Mike. 2007. "The Appliance of Science." Guardian, 14 March. http://www .guardian.co.uk/society/2007/mar/14/scienceofclimatechange.climatechange (accessed 17 February 2012).

- 2009. Why We Disagree About Climate Change: Understanding Controversy Inaction and Opportunity. Cambridge, UK: Cambridge University Press.

IPCC. 2006. Principles Governing IPCC Work. Approved at the Fourteenth Session (Vienna, 1-3 October 1998), amended at the Twenty-First Session (Vienna, 3 and 6-7 November 2003) and at the 25th Session (Mauritius, 26-28 April 2006). Geneva: IPCC. http://www.ipcc.ch/pdf/ipcc-principles/ipcc-principles.pdf (accessed 1 March 2012).

Krauss, Werner, and Hans von Storch. 2012. "Climate Science in a Postnormal Context. EOS, Transactions of the American Geophysical Union 93 (10): 108.

Kuhn, Thomas S. 1962. The Structure of Scientific Revolutions. Chicago, IL: University of Chicago Press.

McIntyre, Steve. 2006. "Hockey Stick Studies." http://climateaudit.org/multiproxypdfs/ (accessed 1 March 2012).

Moser, Susanne C. 2010. "Communicating Climate Change: History, Challenges, Process and Future Directions." Wiley Interdisciplinary Reviews: Climate Change 1 (1): 31-53.

Pearce, Fred. 2011. "Climate Sceptics and Scientists Attempt Peace Deal." 2 February. http://www.newscientist.com/blogs/shortsharpscience/2011/02/climate-scepticsscientists-at.html (accessed 1 March 2012).

Pielke, Roger A., Jr. 2007. The Honest Broker: Making Sense of Science in Policy and Politics. Cambridge, UK: Cambridge University Press.

Post, Senja. 2009. Klimakatastrophe oder Katastrophenklima? Die Berichterstattung über den Klimawandel aus Sicht der Klimaforscher. Baden-Baden, Germany: Nomos.

Ratter, Beate M.W., Katharina H.I. Philipp, and Hans von Storch. 2012. "Between Hype and Decline: Recent Trends in Public Perception of Climate Change." Environmental Science \& Policy 18 (1): 3-8.

Ravetz, Jerome R. 2010. "Climategate: Plausibility and the Blogosphere in the PostNormal Age." 2 February. http://wattsupwiththat.com/2010/02/09/climategateplausibility-and-the-blogosphere-in-the-post-normal-age/ (accessed: 1 March 2012).

- 2012. "Sociology of Science: Keep Standards High." Nature 481 (7379):

25. 
Ryghaug, Marianne, and Tomas N. Skjølsvold. 2010. "The Global Warming of Climate Science: Climategate and the Construction of Scientific Facts." International Studies in the Philosophy of Science 24 (3): 287-307.

Schäfer, Mike S., Ana Ivanova, Inga Schlichting, and Andreas Schmidt. 2012. "Mediatisierung: Medienerfahrungen und -orientierungen deutscher Klimawissenschaftler." Pp. 233-252 in Das Medien-Klima, ed. Irene Neverla and Mike S. Schäfer. Wiesbaden: Springer VS.

Schäfer, Mike S., Ana Ivanova, and Andreas Schmidt. 2011. "Globaler Klimawandel, globale Öffentlichkeit? Medienaufmerksamkeit für den Klimawandel in 23 Ländern." Studies in Communication/Media 1 (1): 133-148.

Schützenmeister, Falk. 2008. Zwischen Problemorientierung und Disziplin: Ein koevolutionäres Modell der Wissenschaftsentwicklung. Bielefeld, Germany: Transcript.

Traufetter, Gerald. 2011. "Versöhnungstagung. Der Klimakrieg kann weitergehen." 31 January. http://www.spiegel.de/wissenschaft/natur/0,1518,742612,00.html (accessed 1 March 2012).

von Storch, Hans. 2009. "Climate Research and Policy Advice: Scientific and Cultural Constructions of Knowledge." Environmental Science \& Policy 12 (7): 741-747.

von Storch, Hans, Insa Meinke, Nico Stehr, Beate Ratter, Werner Krauss, Roger Pielke Jr., Reiner Grundmann, Marcus Reckermann, and Ralf Weisse. 2011. "Regional Climate Services Illustrated with Experiences from Northern Europe." Zeitschrift für Umweltpolitik und Umweltrecht 34 (1): 1-16.

Weingart, Peter, Anita Engels, and Petra Pansegrau. 2000. "Risks of Communication: Discourses on Climate Change in Science, Politics, and the Mass Media." Public Understanding of Science 9 (3): 261-283. 